ISSN $0819-2642$

ISBN 0734024444

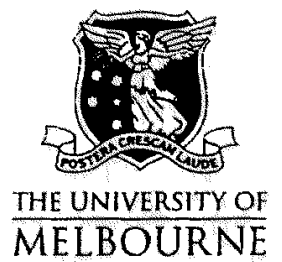

THE UNIVERSITY OF MELBOURNE

DEPARTMENT OF ECONOMICS

RESEARCH PAPER NUMBER 789*

JUNE 2001

\title{
SOME MARKET EFFECTS \\ OF E-COMMERCE
}

by

John Freebaim

Department of Economics The University of Melbourne Melbourne Victoria 3010

Australia. 


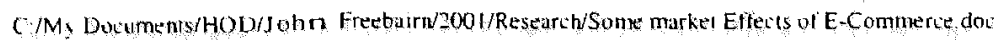

\title{
Some Market Effects of E-Commerce
}

\author{
John Freebairn* \\ Department of Economics \\ The University of Melbourne \\ Victoria 3010 \\ Australia
}

\begin{abstract}
An important characteristic of E-commerce is that it is a form of technological change. The effects of E-commerce induced reductions in business production costs and on seller to buyer transaction costs are assessed. Comparative static models for different market structures are used to assess the effects of E-commerce on prices, quantities, aggregate efficiency gains, and the distribution of benefits and costs. Ultimately consumers are the principle beneficiaries via lower prices. Competitive forces and profit incentives induce firms to adopt cost reducing E-commerce technology.
\end{abstract}




\title{
Some Market Effects of E-Commerce
}

\author{
John Freebairn \\ The University of Melbourne
}

\section{Introduction}

One important characteristic of the growing use of e-commerce is that it is a form of technological change which raises value added per unit of inputs. Broadly, ecommerce embraces "substitution of computer data processing and Internet connections for labour services in the production of economic transactions" (LuckingReily and Spulber, 2001, p.55). Business to business (B2B) e-commerce can improve productivity, for example, by better inventory control and less wastage, by the procurement of more suitable and cheaper inputs, by lower transaction costs, by more effective and lower cost staff training, by better and cheaper access to research and market information, and by facilitating the process of incremental, continuous and evolutionary organisational change (Coppel, 2000, Brynjolfsson and Hitt, 2000, Lucking-Reily and Spulber, 2001). In the first instance B2B e-commerce reduces business production costs (Brookes and Wahhaj, 2000 and Stiglitz, Orszag and Orszag, 2000), and/or increases more valuable output per unit inputs. Business to consumer (B2C) e-commerce can improve productivity by, for example, offering consumers broader choice and greater convenience, by reducing time and costs in making transactions, by reducing handling costs and theft, by use of new price discovery mechanisms, and by facilitating better customer relationships. In the first instance $\mathrm{B} 2 \mathrm{C}$ e-commerce lowers transaction costs or raises the consumer derived demand for goods and services, (Coppel, 2000, Stiglitz, Orszag and Orszag, 2000, and Bakos, 2001). The initial or first round effects of technological change, including ecommerce, induce market reactions affecting prices and quantities of goods and services, and these second round effects influence the aggregate benefits and the distribution of the benefits of e-commerce. 
This paper uses partial equilibrium models of individual products to assess the directions of effect, and to provide a framework for quantifying the magnitudes of effect, of the adoption of e-commerce on market prices and quantities, on aggregate benefits, and on the distribution of the benefits between producers and consumers. Section 2 considers in more detail the first round effects of e-commerce on business costs, consumer demand and transaction costs. While non-parallel curve shifts are possible, for most cases it is concluded that parallel shifts of marginal cost and derived demand curves provide a reasonable approximation of the first round effect of the technological change characteristic of B2B and B2C e-commerce. Sections 3 through 6 evaluate the market effects of successful adoption of e-commerce cost reducing technologies for products in different market structures, namely perfect competition, monopoly, monopolistic competition and some oligopoly models. The distribution of the benefits of e-commerce between producers and consumers vary with the extent of size economies in production and with the industry structure. Some comments on more general equilibrium cross-product effects of e-commerce are made in section 7. A final section provides conclusions.

\section{Cost Shift}

This section explores the effects of productivity growth achieved by e-commerce, especially B2B, on an individual firm's average and marginal cost curves and for an industry with many firms the effects on the industry supply curve. Particular interest is given on whether e-commerce shifts the curves down in a parallel fashion, ie. a constant per unit cost reduction, or pivotly, convergently or otherwise. The focus is on a comparison of costs incurred under the current technology with costs incurred when making use of e-commerce.

Consider initially the effects of e-commerce on costs for a single firm. One set of e-commerce innovations are directed at lowering per unit variable input costs. These include the ability to find and purchase more suitable inputs, better inventory control and less waste, better integration of production stages and of production and marketing stages, and both more effective and less costly training and retraining of staff using multimedia and other electronic means. The effect of input cost reducing technology is to shift the average variable cost, marginal cost and average cost curves 
down by a fixed sum for input cost reductions or proportionally for increases in output per unit input improvements.

Another set of e-commerce innovations are directed to lowering sales and marketing expenses. Examples include web pages for advertising and interactive buyer information searching, facilitating transactions of physical products, and direct transfer of digitised products. Generally, this e-commerce technology is characterised by a large initial set-up fee and a very low marginal cost, (Shapiro and Varian, 1999). To some extent the replaced technology, including more conventional advertising methods, sales persons and clerks, also have these large fixed cost and low marginal cost characteristics, but not as dramatic as for e-commerce. Then, replacement of the old technology with e-commerce, assuming it is profitable for the firm to do so, will result in a fall in variable and marginal costs, perhaps a net increase in fixed or quantity independent costs, and a net fall in average costs.

Some applications of e-commerce are directed primarily to improving productivity of management and of other overheads in the sense of increasing value added per unit input. Productivity gains come from better access to information on production, markets, competitors and research where the information draws on wider sources, is more focussed, is more accurate and is more timely. Further, the additional information may support organisational changes which bring productivity gains across the firm. Management and other overhead productivity improvements may indirectly lower variable and marginal costs in much the same way as already noted for improved productivity of variable inputs, and certainly they will reduce average costs.

The foregoing assessment indicates the pattern of firm cost reductions due to ecommerce will vary with the particular form of technology and individual firm. In many cases a per unit reduction in marginal and average costs will be a close approximation and might be taken as a default option unless particular cases point to a different cost reduction pattern.'

Consider next an industry with many firms, and for simplicity a competitive industry where the industry supply curve is derived from the summation of firm marginal cost curves. In this context, the way in which e-commerce shifts down the industry supply curve depends on cost reductions for each firm and on the location of different firms on the supply curve. As argued by Rose (1980) and Li ndner and Jarrett (1980), in practice it is difficult to allocate firms along an industry supply 
curve. The initial guess that relatively low variable cost firms are inframarginal producers and high variable cost firms are marginal producers ignores likely differences in opportunity returns and costs to firm specific factors. It is likely that low variable cost producers in industry $i$ have high quality managerial and other quasi-fixed inputs with higher opportunity returns in industry $j$; and vice-versa for lower variable cost producers, In such circumstances, Rose and Lindner and Jarrett argue for a parallel or constant per unit reduction on the industry supply curves, unless compelling information to the contrary is provided. Their arguments developed for cost reducing agricultural $R \& D$ also seem relevant for the cost reducing effects of e-commerce.

A more difficult area to assess is whether e-commerce will raise dynamic efficiency associated with more intense competition, less rent seeking, faster adoption of technology and better management and work practices, in addition to the more conventional static cost reduction discussed so far. In one sense e-commerce is a part of globalisation, more vigorous and wider sourced competition, and the faster dispersion of information. Alternatively, e-commerce, alone or more likely along with other technological changes, may be large scale biased, in part because of network extemalities and the increased importance of brand names. More research and experience seems necessary to draw any conclusions about the effects of ecommerce on measures of dynamic efficiency.

\section{Competitive Industry}

Here the most important assumption is that price is set close to marginal cost, either as a consequence of the textbook perfectly competitive model or as a realisation of behaviour in contestable markets with low entry and sunk costs. This section then describes the market reactions to a reduction in marginal costs associated with the successful adoption of cost reducing e-commerce. It uses procedures widely used in studying the effects of R\&D in the agricultural sector (eg. Alston, Norton and Pardey, 1995).

Figure 1 considers the case of $\mathrm{B} 2 \mathrm{~B}$ e-commerce reducing marginal production costs. The initial position with demand $D$ and supply $S$, which also is the sum of firm marginal costs, yields price $\mathrm{P}$ and quantity $\mathrm{Q}$. The e-commerce technological change in net reduces production costs by $k$ per unit output and shifts the suppl y curve down 
to $S^{1}$. Market price falls and quantity rises. Consumers gain $\mathrm{P}^{\prime} \mathrm{PEE}^{\prime}$, producers face lower prices, but gain at least as much from the cost reduction for a net gain of $C P^{1} E^{\prime} G$. Summing, there is an overall society gain of $A B E E^{l} G$. Society gain is the per unit cost reduction times current output, plus a little on the extra output. After market adjustments, the benefits are shared between producers and consumers depending on relative price slopes or elasticities of demand and supply.

The market effects of $\mathrm{B} 2 \mathrm{C}$ e-commerce reductions in seller-buyer transaction costs are illustrated in Figure 2. Here D is the buyer demand for the desired product safely delivered to the consumer and $S$ is producer production cost, and a transaction cost $\mathrm{LM}$ is incurred, giving an initial equilibrium of quantity $\mathrm{Q}$, buyer price on delivery of $\mathrm{P}_{\mathrm{b}}$ and producer receipt price of $\mathrm{P}_{\mathrm{p}}$. Now, suppose the net reduction of transaction costs associated with e-commerce is given by $\mathrm{LM}-\mathrm{NT}=\mathrm{k}$, where $\mathrm{k}$ (as in Figure 1) is the net per unit transaction cost reduction. Output rises, the buyer delivered price falls, and returns to producers rise. Buyers gain $P_{b}{ }^{\prime} P_{b} L N$, producers gain $\mathrm{P}_{\mathrm{p}} \mathrm{P}_{\mathrm{p}}{ }^{1} \mathrm{TM}$, and there is an overall society gain of the sum of terms. Society gains are the per unit cost reduction $\mathrm{k}$ times initial output, plus a little on the extra output. The distribution of these aggregate gains between buyers and sellers depend on the relative price slopes or elasticities of supply and demand.

The hinted out similarity of aggregate benefits from e-commerce reductions in production costs and transaction costs, and the distribution of these benefits, can be shown formally. Gains from a per unit cost reduction of $\mathrm{k}$ to buyers, producers and society, respectively $G_{b}^{c}, G_{p}^{c}$ and $G^{c}$, can be expressed as

$$
\begin{aligned}
G_{b}^{c} & =\left(P-P^{l}\right)\left(Q+\frac{1}{2} \Delta Q\right) \\
& =(s /(s+d)) k\left(Q+\frac{1}{2} \Delta Q\right) \\
G_{p}^{c} & =\left(k-\left(P-P^{l}\right)\right)\left(Q+\frac{1}{2} \Delta Q\right) \\
& =(d /(s+d)) k\left(Q+\frac{1}{2} \Delta Q\right)
\end{aligned}
$$




$$
\begin{aligned}
\mathrm{G}^{\mathrm{c}} & =\mathrm{G}_{\mathbf{b}}^{\mathrm{c}}+\mathrm{G}_{\mathrm{c}}^{\mathrm{c}} \\
& =\mathrm{k}\left(\mathrm{Q}+\frac{1}{2} \Delta \mathrm{Q}\right)
\end{aligned}
$$

where $P$ and $Q$ are the initial market price and quantity, $\Delta Q$ is the increase in market quantity, $\mathrm{k}$ is the per unit cost reduction, $\mathrm{P}^{\prime}$ is the after technology change price, (and $d$ and $s$ are the respective (absolute values of the) elasticities of demand and supply. ${ }^{2}$ Equations (1), (2) and (3) provide key assessments of the individual product effects of e-commerce for competitive markets.

Aggregate or society benefits, $\mathrm{G}^{\mathrm{c}}$, primarily are the e-commerce induced net reduction in per unit production and transactions costs times output, $\mathrm{kQ}$. In most cases the second right hand term of (3), $\frac{1}{2} \mathrm{k} \Delta \mathrm{Q}$, is relatively small. Market price adjustments mean the benefits of e-commerce are partly passed on to buyers. For a constant cost industry for which the elasticity of supply is infinite, ultimately all the cost savings are passed forward to buyers, ie. $G_{b}^{c}=G^{c}$ and $G_{p}^{c}=0$. Where the industry supply curve is upward sloping, some of the benefits are retained by industry fixed factors as higher quasi-rents. The more elastic supply relative to demand, the higher the share of the cost savings passed to buyers.

The competitive model also provides useful insights into the incentives and rewards for individual firms to develop and to adopt e-commerce. Early adopters of successful cost reducing technologies gain most of the cost saving and face small market price falls. Late adopters face the market price falls, with delayed receipt of any cost savings, and non-adopters lose from lower prices. In competitive markets there is a fierce Darwinian "survival of the fittest" favouring early adopters of net cost saving e-commerce with penalties on late and non-adopters and on those initiatives ineffective in lowering costs. The market reactions pass the cost savings forward to buyers, and fully so in the case of near constant cost industries.

\section{Monopoly}

At the other extreme to perfect competition, consider next monopoly. Figure 3 illustrates the single price-setting monopoly case with initial equilibrium at price $\mathrm{P}$ 
technological improvement is shown as reducing marginal cost by $\mathrm{k}$ per unit to $\mathrm{MC}^{\mathrm{J}}$. Then, e-commerce leads to a lower price $\mathrm{P}^{\prime}$ and a larger quantity $\mathrm{Q}^{\prime}$. Buyers gain from the lower price by $P^{\prime} P E E^{1}$. On initial output $Q$ the monopolist loses from the price fall but gains more from the cost reduction, and in addition the firm gains $\mathrm{P}^{1}$ $M C^{l}$ per unit on additional sales, for a net gain of $\mathrm{P}^{\prime} \mathrm{E}^{\prime} \mathrm{GA}-\mathrm{PEFB}$.

Comparing the market price fall and buyer gain under perfect competition and monopoly, both are less for monopoly. Formally, the gain to buyers under monopoly, $\mathrm{G}^{\mathrm{m}}{ }_{\mathrm{b}}$, can be expressed as

$$
\begin{aligned}
\mathrm{G}_{\mathrm{b}}^{\mathrm{m}} & =\left(\mathrm{P}^{1}-\mathrm{P}\right)\left(\mathrm{Q}+\frac{1}{2} \Delta \mathrm{Q}\right) \\
& =(\mathrm{s} /(2 \mathrm{~s}+\mathrm{d})) \mathrm{k}\left(\mathrm{Q}+\frac{1}{2} \Delta \mathrm{Q}\right)
\end{aligned}
$$

where $P$ and $Q$ are the before innovation price and quantity, $P^{1}$ is the after $\mathrm{e}-$ commerce price and $\Delta \mathrm{Q}$ is the increase in output as a result of the $\mathrm{k}$ per unit reduction in marginal cost, $d$ is the demand elasticity and $s$ is the elasticity of the marginal cost curve. Comparing the competitive model gain $\mathrm{G}_{b}^{\mathrm{c}}$ of (1) with the monopoly model gain $G_{b}^{m}$ of (4), the price cut, or first right hand term, is less for monopoly. For a constant marginal cost case, $s=\infty$, only a half of the technology induced cost reduction is passed onto buyers under monopoly whereas all is passed on under competitive behaviour. With a rising marginal cost curve associated with diseconomies of some form, the market price fall and buyer gain is less under both competitive and monopoly markets the more elastic is demand relative to supply or marginal cost. With a monopoly industry, no-more than a half of the marginal cost reduction contributed by e-commerce will be passed forward to buyers.

For some industries e-commerce improves the extra information and opportunities for monopoly producers to develop or to further enhance price discrimination, multiple part tariffs, bundling and other more sophisticated marketing strategies associate with greater customerisation of marketing (Shapiro and Varian, 1999, Lucking-Reily and Spulber, 2001, and Bakos, 2001). As wel] as enhancing producer returns, these innovations also may improve buyer utility as an outcome of better matching buyer needs and improved customer relationships. Detailed and specific case studies will be required to analyse these potential effects of e-commerce, 
and it is unlikely that general results for changes in prices and buyer welfare will be derived.

\section{Monopolistic Competition}

Assessment of the effects of e-commerce reducing marginal and average costs for producers in a monopolistic competitive industry can be considered for the short run and for the Iong run. Individual firm and differentiated product effects for the short run are much as described in the previous section and Figure 3 above for a monopolist. That is, prices fall, but by no more than a half of the reduction in marginal cost, and firm output and sales increase. Beginning from an initial equilibrium of normal returns, or zero economic profit, the reduction in average costs means firm profits rise, with average revenue or price greater than average cost.

In the longer run, the increase in profit following the introduction of e-commerce attracts the entry of new firms and/or scale expansion by existing firms. For a monopolistic competitive industry with constant costs, for example where clone firms can be established, firm entry will continue until market prices fall by the average cost reduction. Here, as for a competitive industry, ultimately all the cost savings of $e$ commerce will be passed forward in full as lower prices to buyers, and buyers become the ultimate beneficiaries of e-commerce technology.

Where the monopolistic competitive industry is characterised by diseconomies of size, for example associated with specific managerial and marketing skills or location advantages, some of the cost savings associated with e-commerce will end up as higher quasi-rents to the scarce production inputs. These higher quasi-rents in turn push up the firm average cost curves and mean that long run market prices fall by less than the initial e-commerce technological change cost reduction.

Because of the relatively free and easy entry of firms in response to changes in profit levels, the response of a monopolistic competitive industry to cost savings associated withe-commerce will be close to a monopoly in the short run and to a competitive industry in the long run. In particular, in the short run less than half of the cost reduction will be passed forward to buyers, but prices will fall further in the longer run. In the extreme case of an industry with no industry specific production factors, all the cost savings will be reaped by buyers as lower prices. Competition 
from existing and potential entrant firms provides a driving force for the adoption of e-commerce technology which reduces production and transaction costs.

\section{Oligopoly}

There are many models of oligopoly behaviour reflecting different assumptions about product differentiation, firm numbers and ease of entry and exit, and about strategic reactions between firms in choosing prices, quantities, promotion, product development, and so forth, (see, for example, Carlton and Perloff, 2000). In terms of assessing the effects of cost reductions associated with the adoption of e-commerce on industry output, prices and the distribution of the benefits of the technological change, this section considers the examples of Coumot and Bertrand behaviour to illustrate that oligopoly industry responses are likely to fall between the perfect competition and monopoly model extremes already assessed. Table 1 provides a summary of the response of market price, and by implication the share of benefits ultimately passed onto buyers, to reductions in firm marginal costs.

Consider initially the simplest case of a fixed two-firm industry, or duopoly, producing a homogenous product. Under Cournot strategic price and quantity behaviour, both the equilibrium market price, and the change in market price following a reduction in marginal cost, falls between the monopoly and perfect competition outcomes; and similarly for industry quantities. For the special case of constant marginal cost, 0.67 of the e-commerce cost reduction would be passed on as lower prices. For an industry with rising marginal costs, a smaller share of any cost reduction, and more so the more elastic demand relative to supply, would be passed forward to buyers. Under Bertrand strategic behaviour, where the firms produce a homogenous product, the competitive model price and quantity outcomes result.

However, in the more realistic case of differential products, Bertrand behaviour generates a price response to lower marginal cost between monopoly and perfect competition outcomes. For the case of constant marginal costs, using the formulae of Table 1, the Bertrand price response equals the monopoly response if the cross-firm price elasticities are zero, ie. $d_{12}=d_{21}=0$, and it approaches the compe titive outcome the larger the cross price elasticities relative to the own price elasticities.

Where market price falls by less than the marginal cost reduction due to the introduction of e-commerce, profits for incumbent firms necessarily rise. Higher 
profits raise the incentive for the entry of new firms, or for existing firms in closely related industries to extend their product range. The event of entry, or even the threat of entry, will work to further increase downward pressures on market prices and to increase the pass through of cost savings to buyers beyond those shown in Table 1 which is drawn on the assumption of constant firm numbers.

There are a number of arguments to consider in assessing whether e-commerce will lower or increase barriers to firm entry in oligopolistic industries. One major claimed advantage of e-commerce when compared with physical inspection in making market transactions is that it effectively lowers barriers of distance and geography in market transactions. Both sellers and buyers have the world at their computer screen, and more information can be accessed about product needs, characteristics and the logistics path. From one perspective, larger geographic markets imply lower barriers to market entry and enhanced competitive pressures. Another perspective is that brand names and other quality assurance measures become more important with ecommerce, and because of size economies in developing and maintaining reputations and because of the advantages of incumbency, barriers to new entrants (and also exit sunk costs) rise. The net effect of these and other changes associated with ecommerce on the ease of firm entry and industry structure are, at this stage, uncertain.

\section{Some More General Equilibrium Effects}

The uneven pattern of price reductions flowing from productivity gains of ecommerce across different industries, and differences of income elasticities of demand combined with the increase in GDP, will result in changes in the industry composition of national output and expenditure.

While $\mathrm{B} 2 \mathrm{~B}$ and $\mathrm{B} 2 \mathrm{C}$-commerce has the potential to reduce costs for all products, the price reductions will vary across the products. Price reductions will be larger for products and industries where the technological productivity gains are relatively more important in reducing production and transaction costs, where industry conduct is closer to the competitive end rather than the monopoly end of the spectrum, and where industry specific production factors causing rising industry marginal costs are relatively unimportant. The mix of product demand will shift with changes in relative product prices, with the magnitudes depending on the pattern of price changes and price elasticities. 
E-commerce, as a form of productivity change, will mean higher GDP than otherwise. Some estimates indicate potential gains from 2 to 5 percent (Department of Communications, Information Technology and the Arts, 1999 and Brookes and Wahhaj, 2000) although the contribution so far seems small (Oliner and Sickel, 2000 and Gordon, 2000). The higher the product income elasticity of demand the greater will be the market growth benefits to particular products and industries of the gains in national productivity.

In addition to these broad industry composition effects driven by changes in relative prices and GDP growth, e-commerce may drive structural changes in other ways. Brief mention already has been given to effects on industry structure. Current indications are that larger firms, and by implication large firm intensive industries, have been quicker in adopting e-commerce than small firms. By reducing market transaction costs e-commerce may reduce the competitive advantage of vertically integrated firms and favour the development of out-sourcing and specialist firm input suppliers.

\section{Conclusions}

In this paper e-commerce is seen as a form of technological change which primarily lowers effective costs of variable inputs, marketing and management. As a reasonable first approximation the effects of e-commerce on product markets with different industry structures are evaluated as changes to price, quantity and economic surplus measures in response to a per unit fall of marginal costs and of lower average costs.

A lower bound estimate of the society benefits of technological change, such as associated with e-commerce, is given by the net cost reduction times current output. Society benefits are somewhat larger because of the resources saved being used for additional production which itself generates extra economic surplus.

Falls in product market prices ultimately redistribute some to all of the ecommerce cost savings to buyers. For the special case of constant cost industries, all of the marginal cost reduction will be passed forward to buyers in the case of competitive and monopolistic competitive industry structures. Under monopoly, it is likely that no more than a half of the cost saving will be passed forward as lower buyer prices. Distribution of the benefits of e-commerce cost reductions to buyers 
will be partial under oligopoly, but closer to the full lower price pass-on outcome the more intense is actual and potential competition as reflected by larger firm numbers, greater product homogeneity, and lower costs and ease of firm entry. Where industry costs involve some diseconomies, a part of the benefits of e-commerce cost reductions will be distributed as higher quasi-rents to the industry specific fixed factors of production. The net GDP growth dividend of technological change as well as the changes in relative product prices will alter the industry composition of national production and expenditure.

The pursuit of higher profit and competitive pressures provide the incentives, rewards and penalties for the adoption of e-commerce which lowers costs and improves buyer utility, and to discard innovations which are not cost effective. Early adopters gain cost savings and experience relatively small price falls initially. In time output expansion encouraged by higher profits drive down product prices. Profits of non-adopters, or even for slow and partial adopters, are squeezed by product price falls and they lose market share to the adopters. 


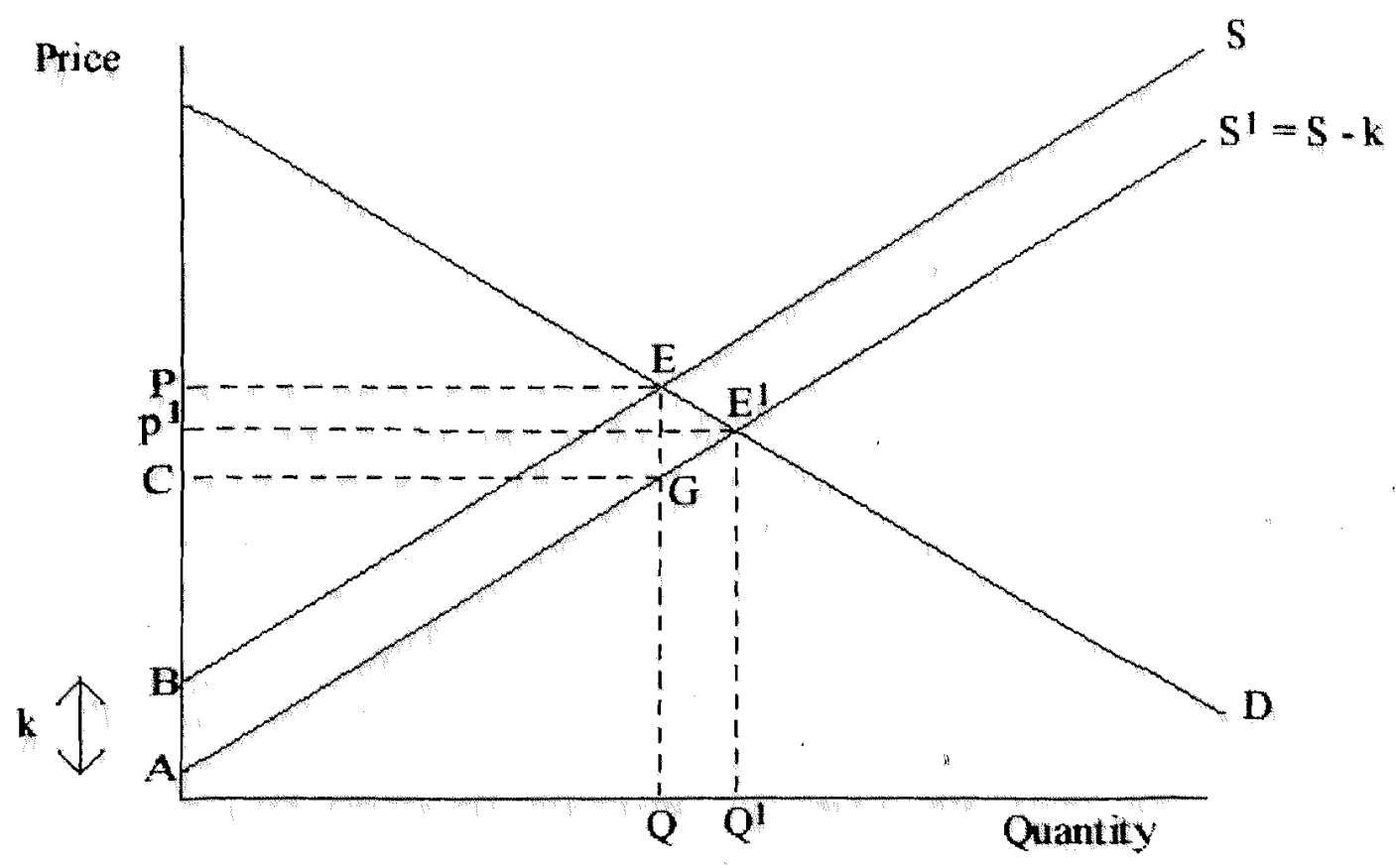

Figure 1: Effects of an e-commerce cost reduction in a competitive market

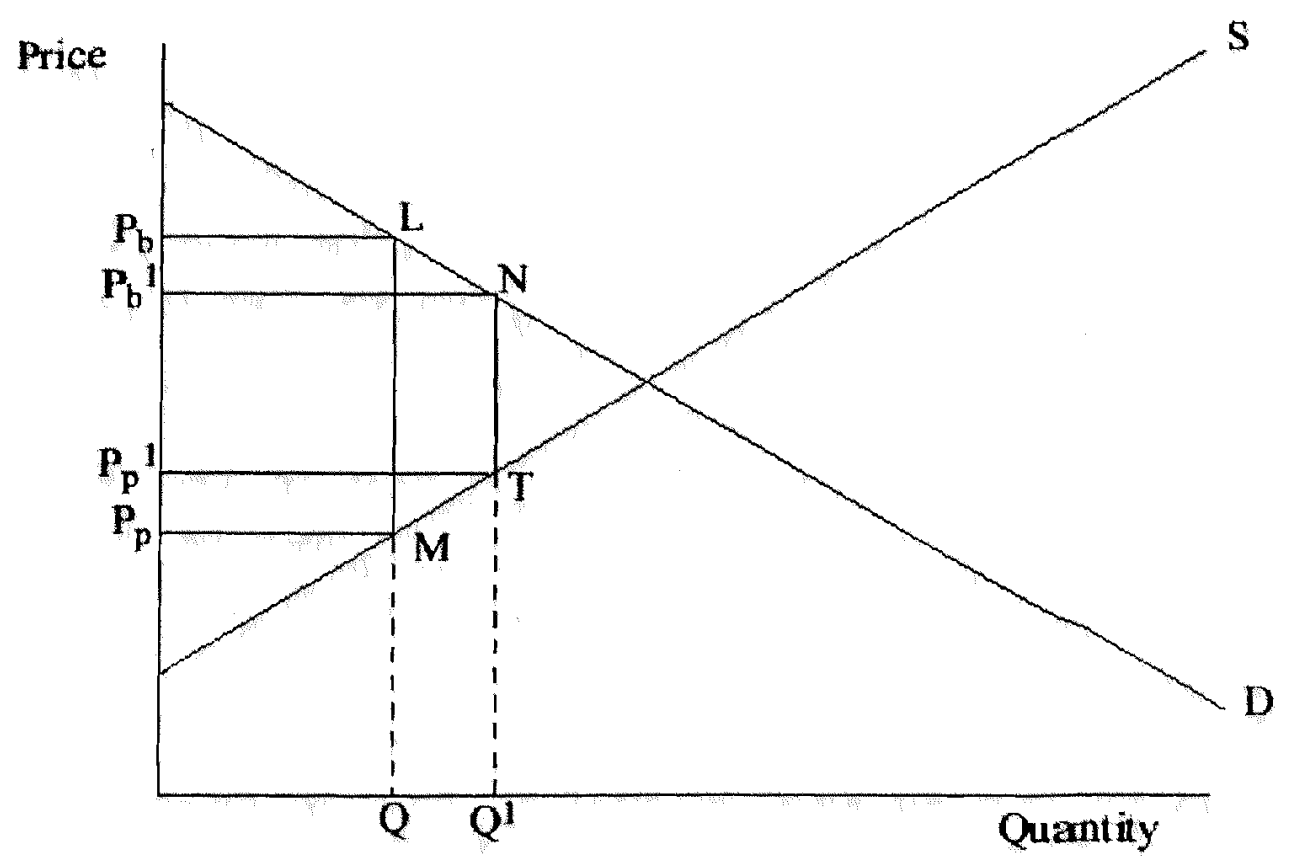

Figure 2: Effects of an e-commerce reduction in transaction costs in a competitive market 


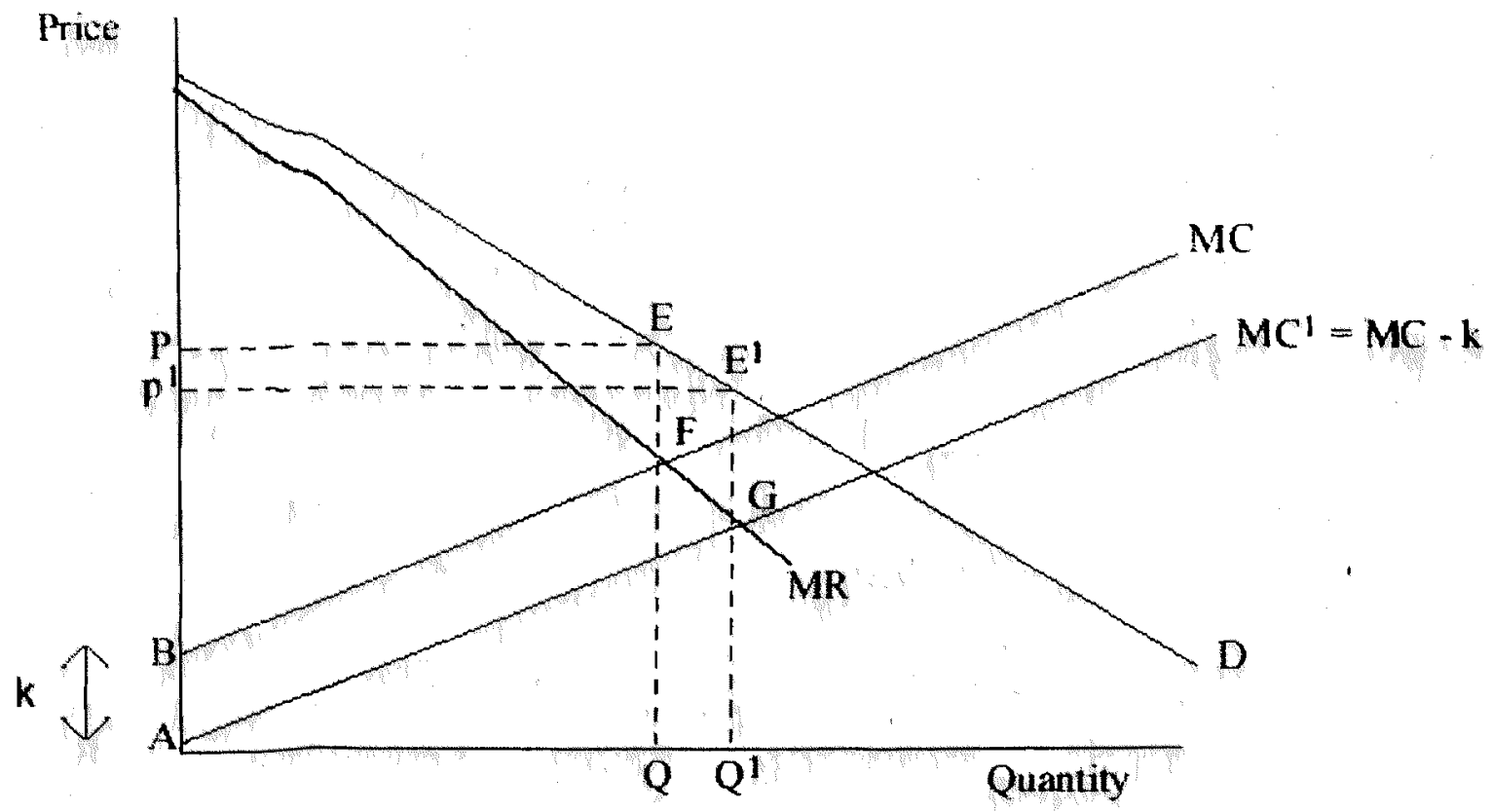

Figure 3: Effects of an e-commerce reduction in production costs in a monopoly market 
Table 1: Market Price Response to Lower Marginal Costs Under Different Industry Structures

\begin{tabular}{|c|c|c|}
\hline \multirow[t]{2}{*}{ Industry Structure } & \multicolumn{2}{|c|}{ Derivative of market price with respect to marginal cost: } \\
\hline & Constant marginal cost & Increasing marginal cost \\
\hline Perfect competition & 1.0 & $\frac{s}{s+d}$ \\
\hline Monopoly & 0.5 & $s$ \\
\hline Monopolistic competition & 1.0 & " \\
\hline $\begin{array}{c}\text { Duopoly - Cournot with } \\
\text { homogenous product }\end{array}$ & 0.67 & $\frac{2 s}{3 s+d}$ \\
\hline $\begin{array}{c}\text { Duopoly - Bertrand with } \\
\text { homogenous products }\end{array}$ & 1.0 & $\frac{s}{s+d}$ \\
\hline $\begin{array}{l}\text { Duopoly - Bertrand with } \\
\text { differentiated products }\end{array}$ & $\frac{2 d_{11} d_{22}+d_{12} d_{22}}{4 d_{11} d_{22}-d_{12} d_{21}}$ & n.c. \\
\hline $\begin{array}{l}\text { Oligopoly - Cournot for } n \\
\text { firms with homogenous } \\
\text { product }\end{array}$ & $\frac{n}{n+1}$ & n.c \\
\hline
\end{tabular}

n.c not computed. $s$ denotes elasticity of supply or of marginal cost curve, d denotes (the absolute value of the) elasticity of demand, and $\mathrm{d}_{\mathrm{ij}}$ denotes (absolute values of the) elasticity of demand for product $i$ (provided by firm i) with respect to price of product $j$, for $i, j=1,2$. 


\section{$\underline{\text { Endnotes }}$}

* I have benefited from the comments of Lu Ding on an earlier version of the paper.

1. Alternative assumptions about the form of the marginal cost curve shift will not affect the estimated price effects and benefits to consumers of e-commerce, but they will alter the measured gains to producers and aggregate gains, when compared with the results reported below for a parallel curve shift. Where the marginal cost curve shift is pivotal or divergent, producer gains are smaller and may become negative, and aggregate gains are smaller but positive. For a convergent marginal cost curve shift, producer and aggregate gains are larger than derived on the assumption of a parallel curve shift.

2. The formulae in (1) and (2), and later in Table 1, have been expressed in terms of price elasticities of demand (absolute value) and supply. Alternatively price slopes could be specified. For simplicity it has been assumed that the elasticities are not affected by the e-commerce technological change. For small cost reductions the constant parameter assumption is likely to be a good approximation, however for large technology cost reductions the assumption may require consideration, and especially if e-commerce also affects industry structure. 


\section{References}

Alston, J., G. Norton and P. Pardey (1995). Science Under Scarcity, Cornell University Press, Ithaca.

Bakos, Y. (2001). The Emerging Landscape for Retail E-Commerce. Journal of Economic Perspectives, 15(1), pp. 69-80.

Brookes, M, and Z. Wahhaj (2000). The Shocking Economic Effect of B2B. Global Economics Paper No.37, Goldman Sacks.

Brynjolfsson, E. and L. Hitt (2000). Beyond Computation: Information Technology, Organisational Transformation and Business Performance. Journal of Economic Perspectives, 14(4), pp. $23-48$.

Carlton, D. and J. Perloff (2000). Modern Industrial Organisation, $3^{\text {rd }}$ ed., AddisonWesley, Reading MA.

Coppel, J. (2000). E-commerce: Impacts and Policy Challenges. Economics Department Working Papers No. 252, OECD, Paris.

Department of Communications, Information Technology and the Arts (1999). Ecommerce Beyond 2000, Australian Government, Canberra.

Gordon, R. (2000). Does the New Economy Measure Up to the Great Inventions of the Past?. Journal of Economic Perspectives, 14(4), pp. $49-74$.

Lindner, R. and F. Jarrett (1980). Supply Shifts and the Size of Research Benefits: Reply. American Journal of Agricultural Economics, 62(4), pp.841 - 844.

Lucking-Reiley, D, and D. Spulber (2001). Business-to-Business Electronic Commerce. Journal of Economic Perspectives. 15(1), pp. 55-68.

Oliner, S. and D. Sickel (2000). The Resurgence of Growth in the Late 1990s: Is Information Technology the Story? Journal of Economic Perspectives, 14(4), pp. $3-22$. 
RESEARCH PAPER SERIES - RECENT PUBLICATIONS IN THE DEPARTMENT OF ECONOMICS

NO. AUTHOR/S

TITLE

DATE

INTERNAT. ISBN NO.

TOTAL WORKING NO. OF PAPER NO.

PAGES

782 John Creedy \& Justin van de Ven

783 Hsiao-chuan Chang

784 John Creedy

785 John Creedy

786 Nilss Olekalns

787 John Stachurski

788 John Stachurski

789 John Freebairn
Taxation, Reranking and Equivalence Scales

International Trade, Productivity Growth, Education and Wage Differentials: A Case Study of Taiwan

The GST and Vertical, Horizontal and Reranking Effects of Indirect Taxation in Australia

Non-uniform Consumption Taxes: A 'Blunt Redistributive Instrument?

An Empirical Investigation of Structural Breaks in the Ex Ante Fisher Effect

Stochastic Growth: Asymptotic Distributions

Log-Linearization of Perturbed Dynamical Systems, with Applications to Optimal Growth

Some Market Effects of E-Commerce
March 2001

March 2001

May 2001

May 2001

May 2001

May 2001

May 2001

June 2001
IWP 719

0734017235

IWP 720

0734017243

IWP 721

0734017251

IWP 722

$073401726 X$

IWP 723

$073402441 X$

IWP 724

0734024428

7

IWP 725

0734024436

12

IWP 726

0734024444

18 